Supporting Information

\title{
A dicobalt(II) single-molecule magnet via a well-designed dual- capping tetrazine radical ligand
}

Binling Yao, ${ }^{a}$ Mukesh Kumar Singh, ${ }^{\mathrm{b}}$ Yi-Fei Deng, ${ }^{\mathrm{a}, *}$ and Yuan-Zhu Zhang, ${ }^{\mathrm{a}, *}$

${ }^{a}$ Department of Chemistry, Southern University of Science and Technology (SUSTech), Shenzhen, 518055, China.

b EastCHEM School of Chemistry, The University of Edinburgh, David Brewster Road, Edinburgh, Scotland, EH9 3FJ, UK.

Email: dengyf@sustech.edu.cn; zhangyz@sustech.edu.cn 
Table S1. Crystallographic data for $\mathbf{1}$.

\begin{tabular}{ll}
\hline & $\mathbf{1}$ \\
\hline Formula & $\mathrm{C}_{64} \mathrm{H}_{54} \mathrm{Co}_{3} \mathrm{~F}_{24} \mathrm{~N}_{14} \mathrm{O}_{10}$ \\
Molecular weight / $\mathrm{g} \mathrm{mol}^{-1}$ & 1812.00 \\
Crystal system & Triclinic \\
Space group & $P \overline{1}$ \\
$a, \AA$ & $11.5865(9)$ \\
$b, \AA$ & $12.6372(10)$ \\
$c, \AA$ & $13.9263(8)$ \\
$a$, deg & $88.061(3)$ \\
$\beta$, deg & $76.686(2)$ \\
$\gamma$, deg & $75.433(2)$ \\
$\mathrm{V}, \AA^{3}$ & $1919.9(2)$ \\
$\mathrm{Z}$ & 1 \\
$D_{\text {cal }} / \mathrm{g}$ cm & \\
temperature, $\mathrm{K}$ & 1.567 \\
$\theta$ range $/{ }^{\circ}$ & $160(2)$ \\
completeness & $2.651-25.411$ \\
residual map, e $\AA^{-3}$ & $98.7 \%$ \\
Goodness-of-fit on $\mathrm{F}^{2}$ & $0.828 /-0.484$ \\
Final indices[I $>2 \sigma(\mathrm{I})]$ & 1.060 \\
$R$ indices (all data) & $R_{1}=0.0480, w R_{2}=0.1283$ \\
\hline
\end{tabular}

Table S2. Selected bond lengths $[\AA]$ and angles $[\mathrm{deg}]$ for $\mathbf{1}$.

\begin{tabular}{llll}
\hline $\mathrm{Co}(1)-\mathrm{O}(2)$ & $2.0843(19)$ & $\mathrm{N}(7)-\mathrm{N}(6)$ & $1.383(3)$ \\
$\mathrm{Co}(1)-\mathrm{N}(1)$ & $2.141(2)$ & $\mathrm{N}(7)-\mathrm{C}(13)$ & $1.314(3)$ \\
$\mathrm{Co}(1)-\mathrm{N}(5)$ & $2.145(2)$ & $\mathrm{N}(6)-\mathrm{C}(13)$ & $1.354(3)$ \\
$\mathrm{Co}(1)-\mathrm{N}(6)$ & $2.0532(19)$ & $\mathrm{Co}(1)-\mathrm{N}(3)$ & $2.104(2)$ \\
$\mathrm{Co}(1)-\mathrm{O}(1)$ & $2.1445(19)$ & & \\
$\mathrm{O}(2)-\mathrm{Co}(1)-\mathrm{O}(1)$ & $84.05(8)$ & $\mathrm{N}(6)-\mathrm{Co}(1)-\mathrm{O}(1)$ & $82.31(8)$ \\
$\mathrm{N}(1)-\mathrm{Co}(1)-\mathrm{N}(5)$ & $82.83(8)$ & $\mathrm{N}(3)-\mathrm{Co}(1)-\mathrm{N}(1)$ & $85.21(8)$ \\
$\mathrm{N}(6)-\mathrm{Co}(1)-\mathrm{O}(2)$ & $97.75(8)$ & $\mathrm{N}(3)-\mathrm{Co}(1)-\mathrm{N}(5)$ & $81.18(8)$ \\
\hline
\end{tabular}

Table S3. Parameters fitted for $\mathbf{1}$ by a generalized Debye model at 3.5 K and under different dc fields.

\begin{tabular}{ccc}
\hline$H / \mathrm{kOe}$ & $\tau / \mathrm{s}$ & $\alpha$ \\
\hline 0.5 & $1.70 \times 10^{-2}$ & 0.36 \\
1.0 & $4.43 \times 10^{-2}$ & 0.25 \\
1.5 & $4.59 \times 10^{-2}$ & 0.14 \\
2.0 & $3.99 \times 10^{-2}$ & 0.10 \\
2.5 & $3.10 \times 10^{-2}$ & 0.10 \\
3.0 & $2.25 \times 10^{-2}$ & 0.10 \\
4.0 & $1.07 \times 10^{-2}$ & 0.13 \\
5.0 & $5.13 \times 10^{-3}$ & 0.16 \\
\hline
\end{tabular}


Table S4. Parameters fitted for $\mathbf{1}$ by a generalized Debye model at $1.5 \mathrm{kOe}$ dc field.

\begin{tabular}{ccc}
\hline$T / \mathrm{K}$ & $\tau / \mathrm{s}$ & $a$ \\
\hline 3.1 & $1.78 \times 10^{-1}$ & 0.30 \\
3.3 & $8.41 \times 10^{-2}$ & 0.22 \\
3.5 & $4.89 \times 10^{-2}$ & 0.16 \\
3.7 & $3.06 \times 10^{-2}$ & 0.12 \\
3.9 & $1.96 \times 10^{-2}$ & 0.10 \\
4.1 & $1.25 \times 10^{-2}$ & 0.09 \\
4.3 & $7.86 \times 10^{-3}$ & 0.08 \\
4.5 & $4.85 \times 10^{-3}$ & 0.07 \\
4.7 & $2.89 \times 10^{-3}$ & 0.08 \\
4.9 & $1.71 \times 10^{-3}$ & 0.09 \\
5.1 & $1.00 \times 10^{-3}$ & 0.10 \\
5.4 & $4.52 \times 10^{-4}$ & 0.11 \\
5.7 & $1.99 \times 10^{-4}$ & 0.14 \\
6.0 & $9.75 \times 10^{-5}$ & 0.14 \\
6.3 & $4.66 \times 10^{-5}$ & 0.16 \\
6.6 & $2.03 \times 10^{-5}$ & 0.22 \\
\hline
\end{tabular}
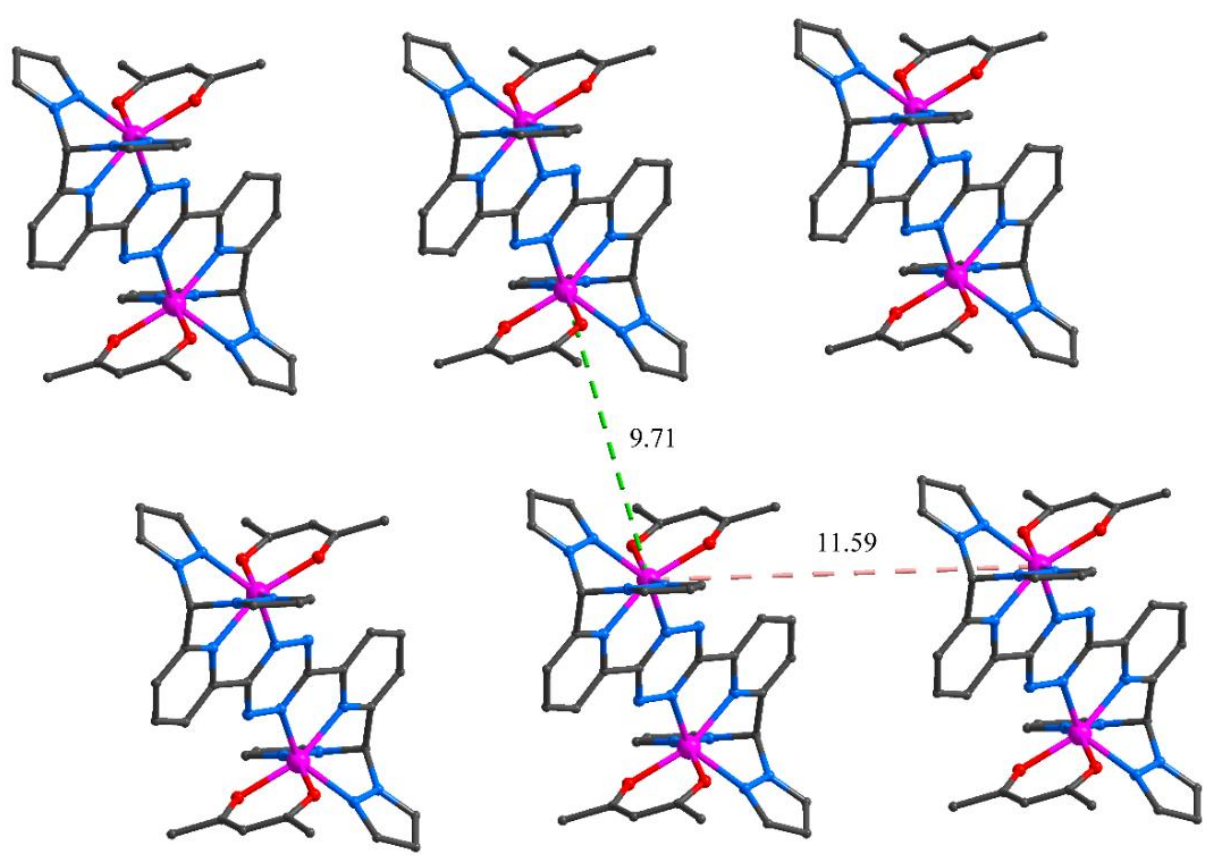

Figure S1. The packing diagram of 1 showing the nearest intermolecular Co $\cdots$ Co separation $(\AA)$. Colour codes: $\mathrm{Co}$, pink; N, blue; $\mathrm{O}$, red; $\mathrm{C}$, grey. All the fluorine and hydrogen atoms, lattice solvents and counterions are omitted for clarity. 


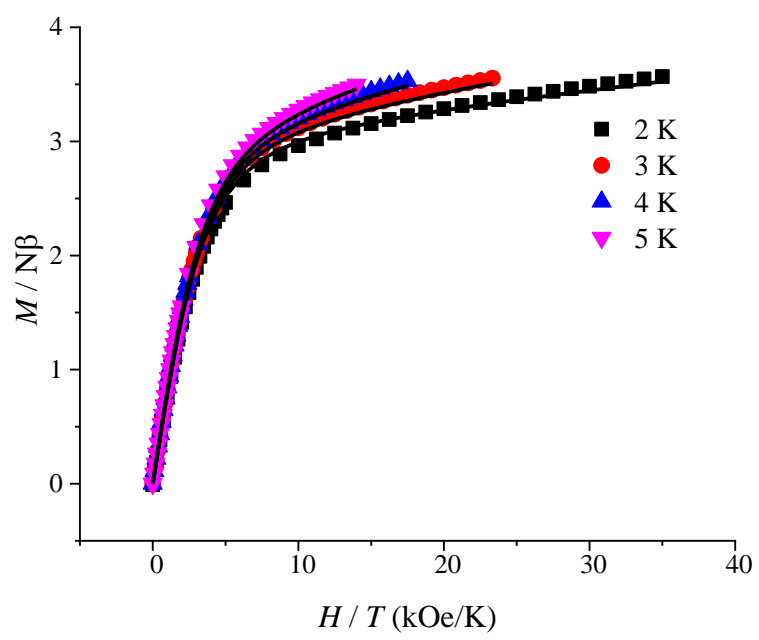

Figure S2. Reduced magnetization data for 1 at $2-5 \mathrm{~K}$. The solid lines represent the best fit to the data using the parameters given in the main text.

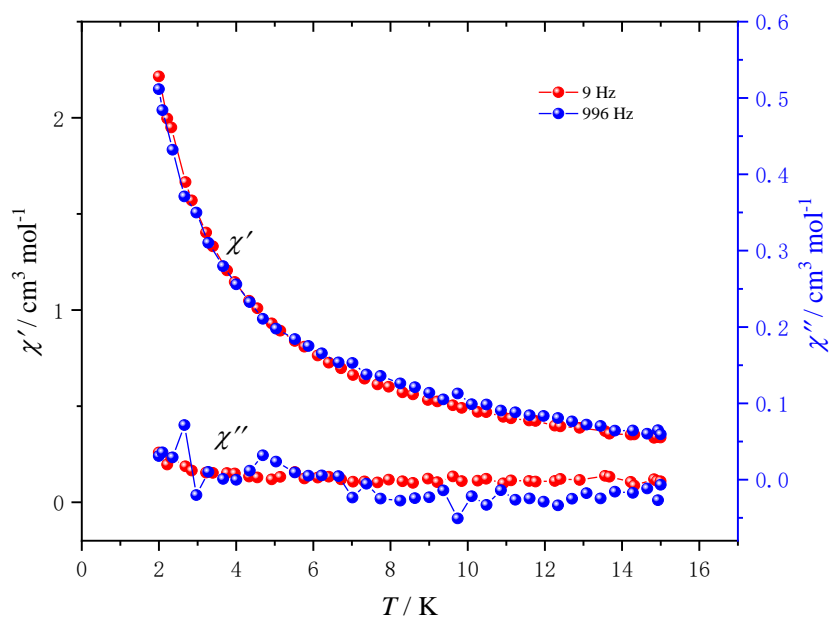

Figure S3. Temperature dependence of the in-phase $\left(\chi^{\prime}\right)$ and out-of-phase $\left(\chi^{\prime \prime}\right)$ ac susceptibility for 1 under zero $\mathrm{dc}$ field. The lines are guides to the eyes.

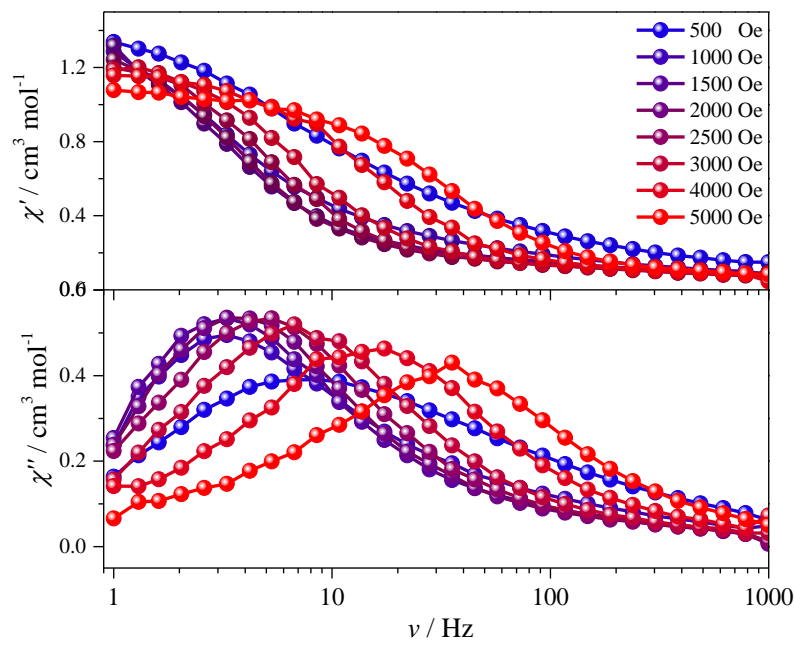

Figure S4. Frequency dependence of the in-phase $\left(\chi^{\prime}\right)$ and the out-of-phase $\left(\chi^{\prime \prime}\right)$ ac susceptibility for $\mathbf{1}$ at $3.5 \mathrm{~K}$ and under different $\mathrm{dc}$ fields. The lines are guides to the eyes. 


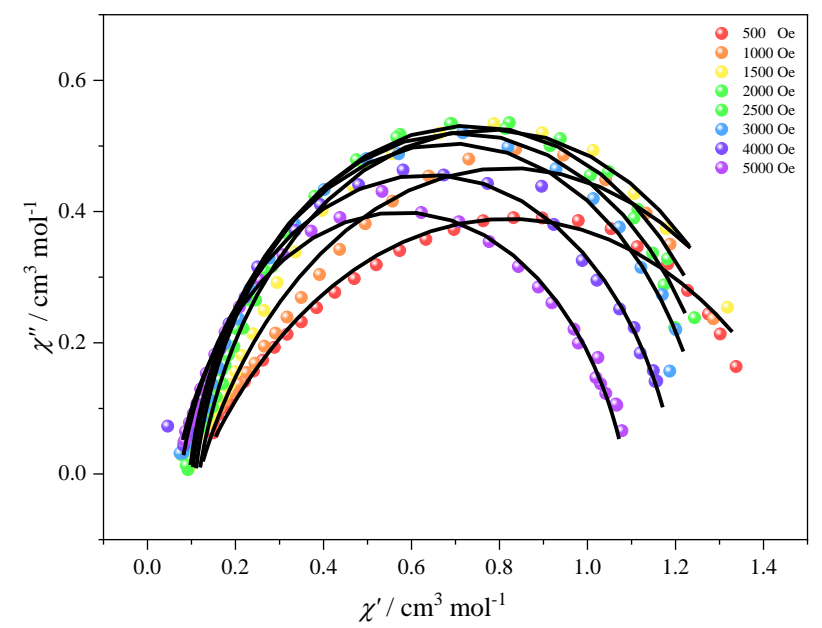

Figure S5. The Cole-Cole plots of $\mathbf{1}$ at $3.5 \mathrm{~K}$ with an applied dc field from 500 to $5000 \mathrm{Oe}$. The lines represent the fit to the data.

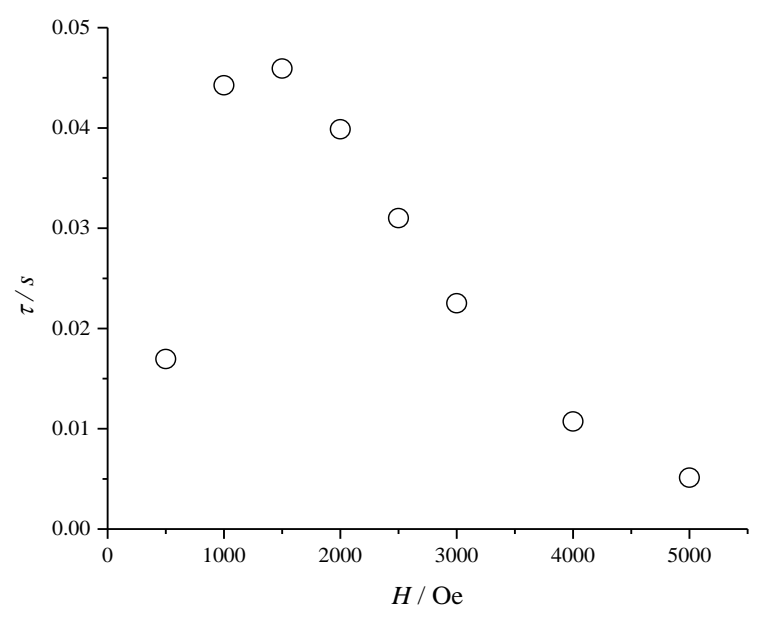

Figure S6. Field dependence of the relaxation time for $\mathbf{1}$ at $3.5 \mathrm{~K}$ and under different dc fields.

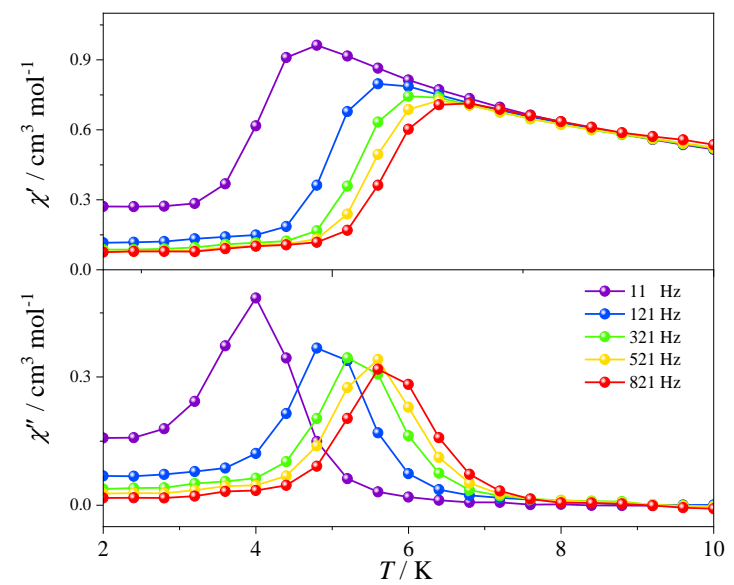

Figure S7. Temperature dependence of the in-phase $\left(\chi^{\prime}\right)$ and out-of-phase $\left(\chi^{\prime \prime}\right)$ ac susceptibility for $\mathbf{1}$ at 1500 Oe $\mathrm{dc}$ field. The lines are guides to the eyes. 


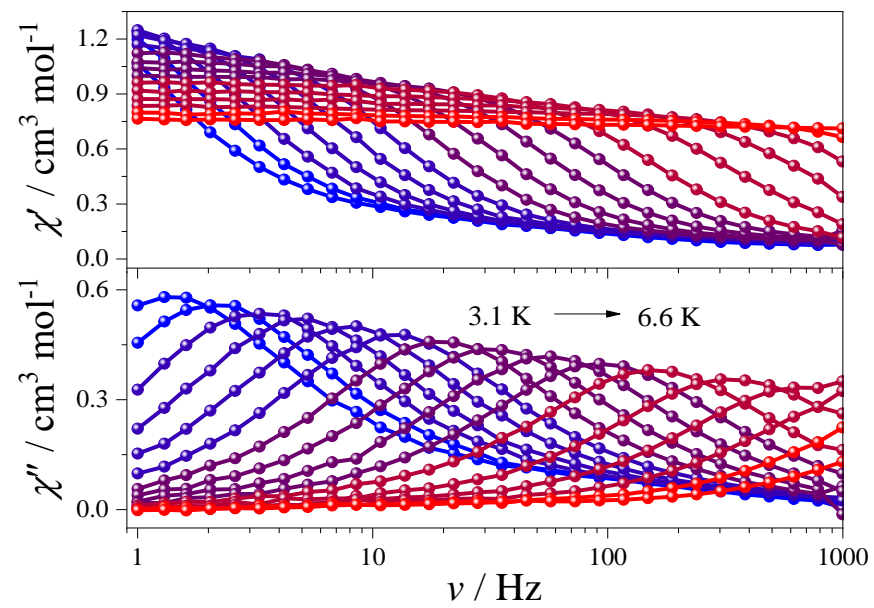

Figure S8. Frequency dependence of the in-phase $\left(\chi^{\prime}\right)$ and out-of-phase $\left(\chi^{\prime \prime}\right)$ ac susceptibility for $\mathbf{1}$ at 1500 Oe dc field. The lines are guides to the eyes.

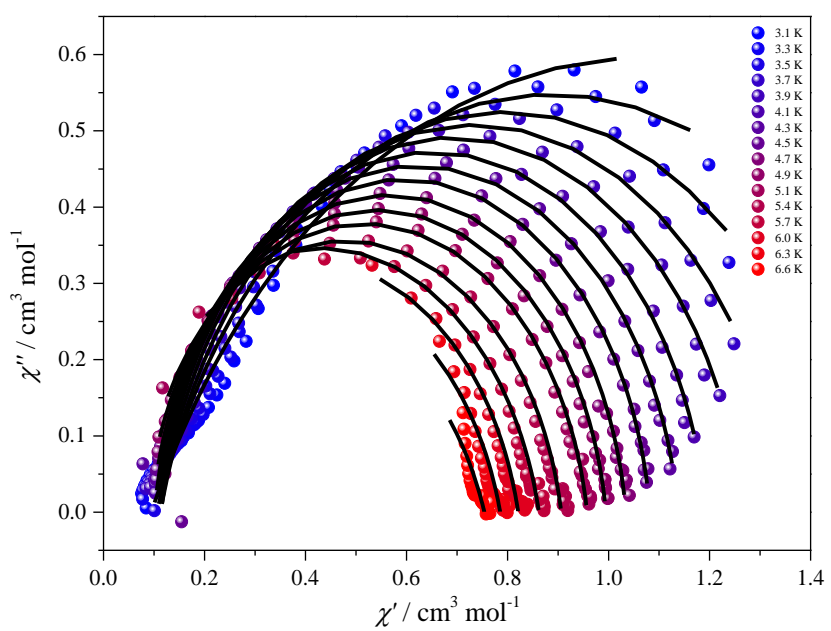

Figure S9. The Cole-Cole plots of $\mathbf{1}$ at 1500 Oe dc field. The lines represent the fit to the data.

\section{Computational Details}

For complex 1, the zero field splitting parameters for each $\mathrm{Co}(\mathrm{II})$ centers are estimated using the ORCA software suite (version ORCA 4.0) on models (Figure S9) made from the XRD structure of $1 .{ }^{1}$ The zeroth-order regular approximation (ZORA) method along with ZORA contracted version of basis set (ZORA-def2-TZVP for Co and ZORA-def-SVP for rest of the elements) has been used for the resolution of identity (RI) approximation to estimate the anisotropy parameters. ${ }^{2}$ For State-average complete active space self-consistent field (SA-CASSCF) calculations for each $\mathrm{Co}$ (II) centers, five d-orbitals with seven electrons (CAS (7electrons/5-3d-orbitals)) were considered in the active space. Ten quartet and forty doublet roots are considered during CASSCF calculations. To consider the dynamic correlation, we have performed the $2^{\text {nd }}$ order $\mathrm{N}$-electron valence perturbation theory which is known to estimate the zero-field splitting parameter accurately. ${ }^{3}$

To estimate the single ion anisotropy parameters, we have also performed $a b$ initio CASSCF ${ }^{4}+\mathrm{RASSI}_{-\mathrm{SO}^{5}+}$ SINGLE_ANISO ${ }^{6}$ calculations on the X-ray structures of 1. During SINGLE_ANISO calculations, the paramagnetic ion(s) other than the center in which we are interested is replaced by diamagnetic ions $\left(\mathrm{Zn}^{\mathrm{II}}\right)$. The basis set used for the $a b$ initio calculations are [H.ANO-RCC...2s], [C.ANO-RCC...3s2p], [F.ANO-RCC...3s 2 p], 
[N.ANO-RCC...3s $2 \mathrm{p} 1 \mathrm{~d}], \quad$ [O.ANO-RCC...3s $2 \mathrm{p} 1 \mathrm{~d}], \quad$ [Zn.ANO-RCC...5s $4 \mathrm{p} 2 \mathrm{~d}] \quad$ and $\quad$ [Co.ANORCC...6s5p3d2f1g]. Seven electrons in seven active $3 \mathrm{~d}$ orbitals are used to perform CASSCF calculations on a Co(II)-mononuclear fragment. In the RASSI-SO step, 10 quartet and 40 doublet roots are used.7 To consider relaxation processes beyond the single-ion, we have considered factors such as $\mathrm{Co}$ (II)-radical(s-tetrazine) and $\mathrm{Co}$ (II)-Co(II) exchange couplings in the CASSCF calculations. We have used $a b$ initio POLY_ANISO program, which uses the Lines model to fit the experimental susceptibility data to estimate the magnetic exchange interactions $(J s)$ between all paramagnetic ions for $\mathbf{1}$. This uses the $a b$ initio computed parameters of the $\mathrm{Co}$ (II) single-ion. During magnetic susceptibility fitting, for radical center, we use an isotropic value of $\mathrm{g}_{\mathrm{zz}}=2.000$. $^{8}$

To further reconfirm the magnetic exchange coupling values, we perform density functional theory (DFT) calculations on 1 using Gaussian 16 suite of program. ${ }^{9}$ We have used two different methodologies 1) the hybrid B3LYP functional ${ }^{10}$ together with TZV basis set ${ }^{11}$ and 2) B3LYP* functional ${ }^{12}$ with def2-TZVP basis set ${ }^{13}$ for all elements during the single point calculations. We use the trustworthy broken symmetry approach ${ }^{8,14}$ to estimate the $\mathrm{Co}$ (II)-radical(s-tetrazine) magnetic exchange. Whereas, diamagnetic substitution is used to estimate the $\mathrm{Co}$ (II)-Co(II) magnetic interaction, where we replace the anionic radical centre with neutral non radical centre. ${ }^{8}$ This results in overall +2 charge on the model system.

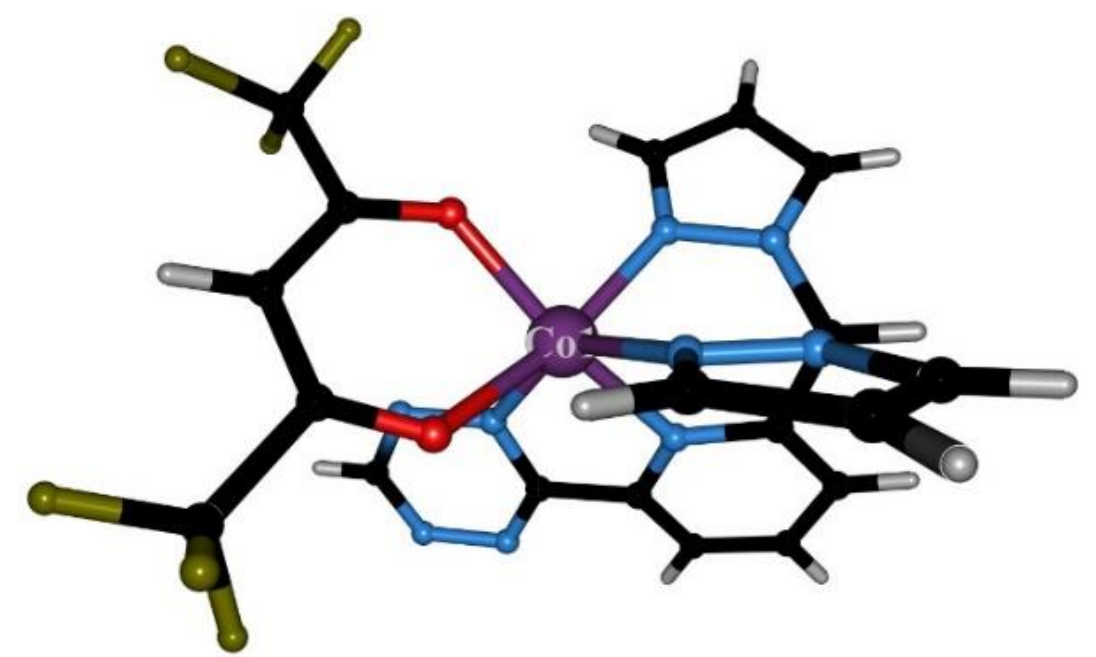

Figure S10. Model for Col center created from the X-ray structure of $\mathbf{1}$ to perform ab initio CASSCF/NEVPT2 calculations.

Table S5. The NEVPT2 transition energies of the ligand field states for both Co(II) centres of $\mathbf{1}$ and its contributions to $D$ and $E / D$.

\begin{tabular}{|c|c|c|c|c|}
\hline \multicolumn{5}{|c|}{$D=-42.6 \mathrm{~cm}-1 ; E / D=0.09$} \\
\hline $\begin{array}{c}g_{\mathrm{xx}}, g_{\mathrm{yy}}, g_{\mathrm{zz}}\left(g_{\text {iso }}\right)=2.085,2.163,2.635(2.294) \\
\text { NEVPT2 energy levels cm } \\
1\end{array}$ & Multiplicity & Root & $\begin{array}{c}\text { Contribution to } D \\
\mathrm{~cm}^{-1}\end{array}$ & $\begin{array}{c}\text { Contribution to } \\
E / D\end{array}$ \\
\hline 0.0 & 4 & 0 & 0.0 & 0.0 \\
\hline 1451.9 & 4 & 1 & -59.2 & 0.1 \\
\hline 4973.4 & 4 & 2 & 6.3 & -6.3 \\
\hline 9703.2 & 4 & 3 & 4.8 & 4.5 \\
\hline 10209.1 & 4 & 4 & 1.7 & -2.0 \\
\hline 10926.7 & 4 & 5 & 0.9 & 0.5 \\
\hline 12837.2 & 2 & 0 & 0.1 & -0.1 \\
\hline
\end{tabular}




\begin{tabular}{|c|c|c|c|c|}
\hline 13748.8 & 2 & 1 & 0.0 & 0.0 \\
\hline 17801.3 & 4 & 6 & 0.0 & 0.0 \\
\hline 19139.2 & 2 & 2 & 0.0 & 0.0 \\
\hline 19592.2 & 2 & 3 & 0.6 & -0.9 \\
\hline 20029.1 & 2 & 4 & 0.8 & 0.8 \\
\hline 20742.0 & 2 & 5 & 0.0 & 0.0 \\
\hline 21137.4 & 2 & 6 & 0.6 & 0.0 \\
\hline 22074.4 & 2 & 7 & 1.8 & 0.0 \\
\hline 22699.8 & 4 & 7 & 0.9 & 0.0 \\
\hline 23929.7 & 4 & 8 & 0.6 & 0.0 \\
\hline 24312.8 & 2 & 9 & -1.2 & 1.2 \\
\hline 24831.1 & 4 & 9 & -1.8 & -1.8 \\
\hline 24841.2 & 2 & 11 & 0.0 & 0.2 \\
\hline 24844.6 & 2 & 10 & -0.1 & 0.4 \\
\hline 26864.8 & 2 & 8 & 0.2 & 0.0 \\
\hline 28715.0 & 2 & 12 & 0.3 & 0.0 \\
\hline 29384.8 & 2 & 13 & 0.0 & 0.0 \\
\hline 30033.3 & 2 & 14 & -0.1 & 0.2 \\
\hline 30523.7 & 2 & 15 & 0.4 & 0.0 \\
\hline 31356.3 & 2 & 16 & 0.0 & 0.0 \\
\hline 31692.1 & 2 & 17 & 0.0 & 0.0 \\
\hline 32717.8 & 2 & 18 & 0.0 & 0.0 \\
\hline 32780.5 & 2 & 19 & 0.5 & 0.0 \\
\hline 33561.6 & 2 & 20 & -0.9 & 0.4 \\
\hline 33968.5 & 2 & 21 & -0.8 & -0.3 \\
\hline 35395.5 & 2 & 22 & 0.0 & 0.0 \\
\hline 36005.6 & 2 & 23 & 0.0 & 0.0 \\
\hline 38333.7 & 2 & 24 & 0.0 & 0.0 \\
\hline 38504.6 & 2 & 25 & 0.1 & 0.0 \\
\hline 39062.9 & 2 & 26 & 0.1 & 0.0 \\
\hline 39576.6 & 2 & 27 & 0.0 & 0.0 \\
\hline 43012.1 & 2 & 28 & 0.1 & 0.0 \\
\hline 43588.4 & 2 & 29 & 0.0 & 0.0 \\
\hline 44547.8 & 2 & 30 & -0.1 & 0.0 \\
\hline 45095.8 & 2 & 31 & 0.0 & 0.0 \\
\hline 45407.5 & 2 & 32 & 0.0 & 0.0 \\
\hline 46342.5 & 2 & 33 & 0.0 & 0.0 \\
\hline 47656.2 & 2 & 34 & 0.0 & 0.0 \\
\hline 64748.7 & 2 & 35 & 0.0 & 0.0 \\
\hline 65523.3 & 2 & 36 & 0.0 & 0.0 \\
\hline 66652.4 & 2 & 37 & 0.0 & 0.0 \\
\hline 67798.6 & 2 & 38 & 0.0 & 0.0 \\
\hline 68386.4 & 2 & 39 & 0.0 & 0.0 \\
\hline
\end{tabular}


Table S6. DFT calculated $J$ values based on two well known DFT methodologies (B3LYP/TZV and $\mathrm{B} 3 L Y P^{*} /$ def2-TZVP). It is important to note here that both methodologies suggest strong antiferromagnetic interaction between $\mathrm{Co}$ (II)-Radical centres and weak antiferromagnetic interaction between $\mathrm{Co}(\mathrm{II})$ - $\mathrm{Co}$ (II) centres.

\begin{tabular}{cc}
\hline & DFT \\
\hline$J_{1} \mathrm{~cm}^{-1}$ & $-48.9(\mathrm{~B} 3 \mathrm{LYp} / \mathrm{TZV}) ;-71.2\left(\mathrm{~B} 3 L Y P^{*} /\right.$ def2-TZVP $)$ \\
$J_{2} \mathrm{~cm}^{-1}$ & $-10.0(\mathrm{~B} 3 \mathrm{LYP} / \mathrm{TZV}) ;-3.4\left(\mathrm{~B} 3 \mathrm{LYP}^{*} / \mathrm{def} 2-\mathrm{TZVP}\right)$ \\
\hline
\end{tabular}

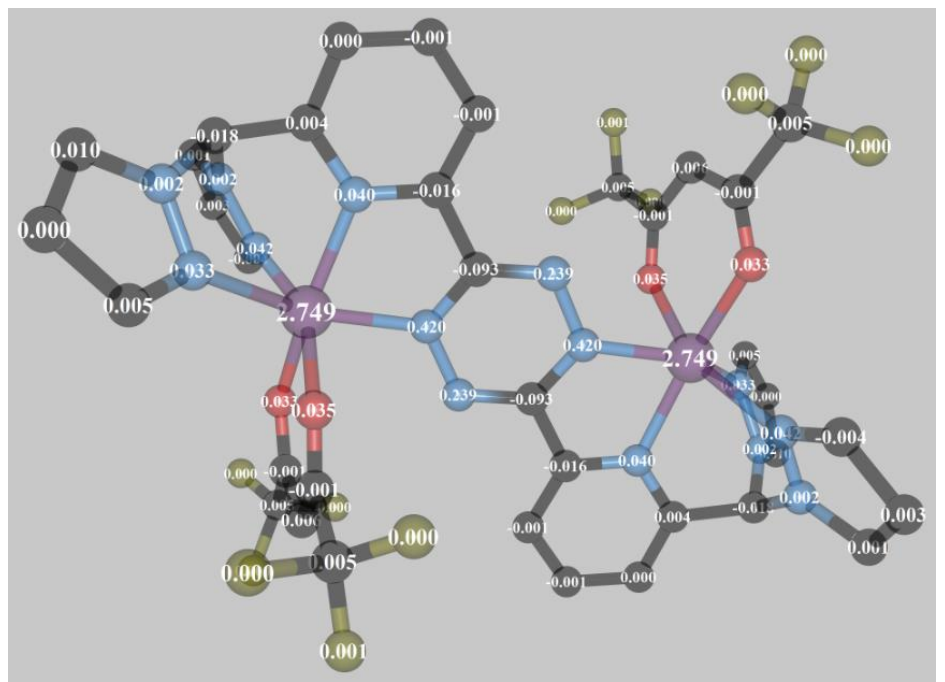

Figure S11. DFT computed spin density values for 1. A dominant spin delocalization mechanism is observed.

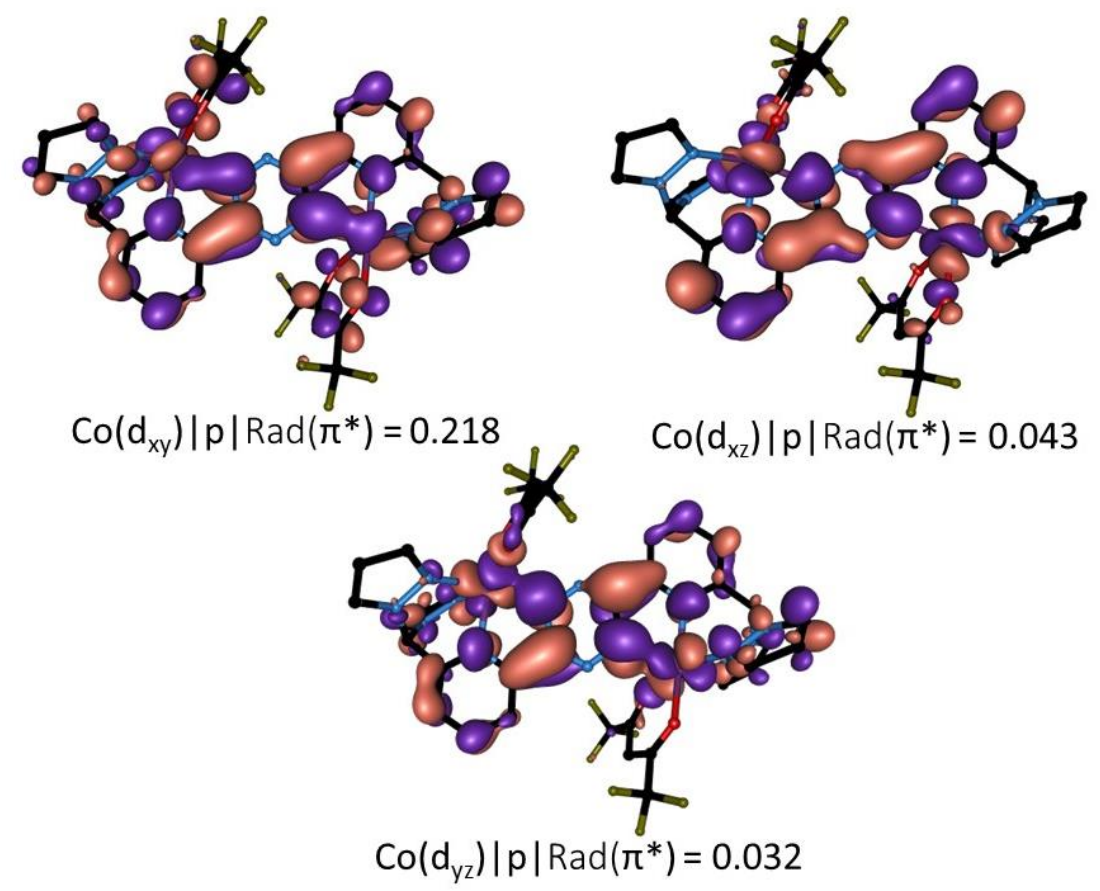

Figure S12. DFT computed overlap integral $\left(\left|S_{\mathrm{ab}}\right|\right)$ calculations using the singly occupied ligand and metal based molecular orbitals. One of the interaction $\left(\operatorname{Co}\left(\mathrm{d}_{\mathrm{xy}}\right)|\mathrm{p}| \operatorname{Rad}\left(\pi^{*}\right)\right)$ is found to be very strong leading to strong Co(II)-radical(s-tetrazine) antiferromagnetic interactions. 
Note: We have used the CASSCF calculated SH parameters in PHI to simulate the energy levels. The ground to the first excited state energy separation is found to be $67.1 \mathrm{~cm}^{-1}$ and is in close agreement with the experimental energy barrier $\left(69 \mathrm{~cm}^{-1}\right)$.

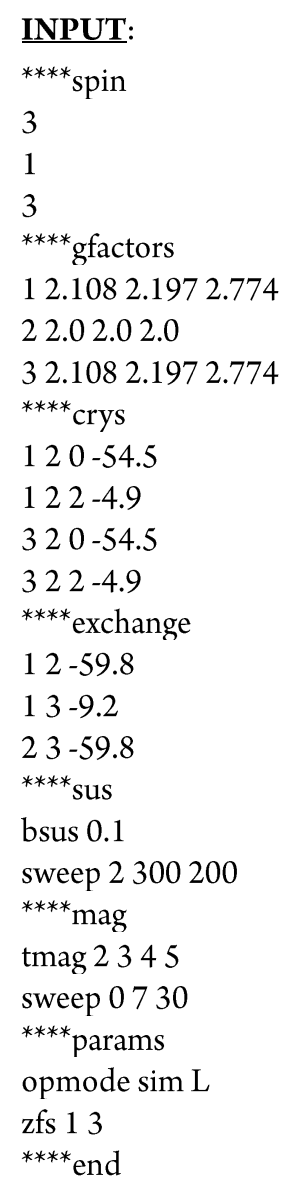

\begin{tabular}{|c|}
\hline Energy levels $\left(\mathrm{cm}^{-1}\right)$ \\
\hline 0.0 \\
\hline 67.1 \\
\hline 68.1 \\
\hline 102.4 \\
\hline 112.7 \\
\hline 202.7 \\
\hline 225.0 \\
\hline 275.9 \\
\hline 341.2 \\
\hline 401.4 \\
\hline 408.9 \\
\hline 438.4 \\
\hline 503.4 \\
\hline 572.8 \\
\hline 608.6 \\
\hline
\end{tabular}

\section{References}

1. Neese, F., The ORCA program system. WIREs Comput. Mol. Sci. 2012, 2, 73-78.

2. (a) Weigend, F.; Ahlrichs, R., Balanced basis sets of split valence, triple zeta valence and quadruple zeta valence quality for $\mathrm{H}$ to $\mathrm{Rn}$ : Design and assessment of accuracy. Phys. Chem. Chem. Phys. 2005, 7, 3297-3305; (b) van Wüllen, C., Molecular density functional calculations in the regular relativistic approximation: Method, application to coinage metal diatomics, hydrides, fluorides and chlorides, and comparison with first-order relativistic calculations. J. Chem. Phys. 1998, 109, 392-399.

3. Herchel, R.; Vahovska, L.; Potocnak, I.; Travnicek, Z., Slow magnetic relaxation in octahedral cobalt(II) field-induced single-ion magnet with positive axial and large rhombic anisotropy. Inorg. Chem. 2014, 53, 58965898.

4. Swerts, B.; Chibotaru, L. F.; Lindh, R.; Seijo, L.; Barandiaran, Z.; Clima, S.; Pierloot, K.; Hendrickx, M. F. A., Embedding Fragment ab Initio Model Potentials in CASSCF/CASPT2 Calculations of Doped Solids: Implementation and Applications. J. Chem. Theory. Comput. 2008, 4, 586-594.

5. Malmqvist, P. Å.; Roos, B. O.; Schimmelpfennig, B., The restricted active space (RAS) state interaction approach with spin-orbit coupling. Chem. Phys. Lett. 2002, 357, 230-240.

6. (a) Chibotaru, L. F.; Ungur, L. SINGLE_ANISO Program, KU Lenven, Belgium, 2007; (b) Ungur, L.; 
Chibotaru, L. F. http://www.molcas.org/documentation/manual/node105.html; (c) Ungur, L.; Lin, S.-Y.; Tang, J.; Chibotaru, L. F., Single-molecule toroics in Ising-type lanthanide molecular clusters. Chem. Soc. Rev. 2014, 43, 6894-6905; (d) Chibotaru, L. F.; Ungur, L., Ab initio calculation of anisotropic magnetic properties of complexes. I. Unique definition of pseudospin Hamiltonians and their derivation. J. Chem. Phys. 2012, 137, 064112; (e) Chibotaru, L. F.; Ceulemans, A.; Bolvin, H., Unique Definition of the Zeeman-Splitting $g$ Tensor of a Kramers Doublet. Phys. Rev. Lett. 2008, 101, 033003; (f) Aquilante, F.; Autschbach, J.; Carlson, R. K.; Chibotaru, L. F.; Delcey, M. G.; De Vico, L.; Fdez. Galván, I.; Ferré, N.; Frutos, L. M.; Gagliardi, L.; Garavelli, M.; Giussani, A.; Hoyer, C. E.; Li Manni, G.; Lischka, H.; Ma, D.; Malmqvist, P. Å.; Müller, T.; Nenov, A.; Olivucci, M.; Pedersen, T. B.; Peng, D.; Plasser, F.; Pritchard, B.; Reiher, M.; Rivalta, I.; Schapiro, I.; Segarra-Martí, J.; Stenrup, M.; Truhlar, D. G.; Ungur, L.; Valentini, A.; Vancoillie, S.; Veryazov, V.; Vysotskiy, V. P.; Weingart, O.; Zapata, F.; Lindh, R., Molcas 8: New capabilities for multiconfigurational quantum chemical calculations across the periodic table. J. Comput. Chem.2016,37, 506-541; (g) Aquilante, F.; De Vico, L.; Ferré, N.; Ghigo, G.; Malmqvist, P.-å.; Neogrády, P.; Pedersen, T. B.; Pitoňák, M.; Reiher, M.; Roos, B. O.; Serrano-Andrés, L.; Urban, M.; Veryazov, V.; Lindh, R., MOLCAS 7: The Next Generation. J. Comput. Chem. 2010, 31, 224-247; (h) Duncan, J. A., MOLCAS 7.2. J. Am. Chem. Soc. 2009, 131, 2416-2416; (i) Veryazov, V.; Widmark, P.-O.; Serrano-Andrés, L.; Lindh, R.; Roos, B. O., 2MOLCAS as a development platform for quantum chemistry software. Int. J. Quantum. Chem. 2004, 100, 626635; (j) Karlström, G.; Lindh, R.; Malmqvist, P.-Å.; Roos, B. O.; Ryde, U.; Veryazov, V.; Widmark, P.-O.; Cossi, M.; Schimmelpfennig, B.; Neogrady, P.; Seijo, L., MOLCAS: a program package for computational chemistry. Comput. Mater. Sci. 2003, 28, 222-239; (k) Roos, B. O.; Lindh, R.; Malmqvist, P.-Å.; Veryazov, V.; Widmark, P.O.; Borin, A. C., New Relativistic Atomic Natural Orbital Basis Sets for Lanthanide Atoms with Applications to the Ce Diatom and LuF. J. Phys. Chem. A 2008, 112, 11431-11435; (1) Bernot, K.; Luzon, J.; Bogani, L.; Etienne, M.; Sangregorio, C.; Shanmugam, M.; Caneschi, A.; Sessoli, R.; Gatteschi, D., Magnetic Anisotropy of Dysprosium(III) in a Low-Symmetry Environment: A Theoretical and Experimental Investigation. J. Am. Chem. Soc. 2009, 131, 5573-5579.

7. (a) Singh, M. K.; Shukla, P.; Khatua, M.; Rajaraman, G., A Design Criteria to Achieve Giant Ising-Type Anisotropy in $\mathrm{Co}^{\mathrm{II}}$-Encapsulated Metallofullerenes. Chem. Eur. J. 2020, 26, 464-477; (b) Yao, B.; Singh, M. K.; Deng, Y.-F.; Wang, Y.-N.; Dunbar, K. R.; Zhang, Y.-Z., Trigonal Prismatic Cobalt(II) Single-Ion Magnets: Manipulating the Magnetic Relaxation Through Symmetry Control. Inorg. Chem. 2020, 59, 8505-8513.

8. Singh, M. K.; Yadav, N.; Rajaraman, G., Record high magnetic exchange and magnetization blockade in $\mathrm{Ln}_{2} @ \mathrm{C}_{79} \mathrm{~N}(\mathrm{Ln}=\mathrm{Gd}(\mathrm{III})$ and $\mathrm{Dy}(\mathrm{III}))$ molecules: a theoretical perspective. Chem Commun. 2015, 51, 17732 17735.

9. Frisch, M. J.; Trucks, G. W.; Schlegel, H. B.; Scuseria, G. E.; Robb, M. A.; Cheeseman, J. R.; Scalmani, G.; Barone, V.; Petersson, G. A.; Nakatsuji, H.; Li, X.; Caricato, M.; Marenich, A. V.; Bloino, J.; Janesko, B. G.; Gomperts, R.; Mennucci, B.; Hratchian, H. P.; Ortiz, J. V.; Izmaylov, A. F.; Sonnenberg, J. L.; Williams; Ding, F.; Lipparini, F.; Egidi, F.; Goings, J.; Peng, B.; Petrone, A.; Henderson, T.; Ranasinghe, D.; Zakrzewski, V. G.; Gao, J.; Rega, N.; Zheng, G.; Liang, W.; Hada, M.; Ehara, M.; Toyota, K.; Fukuda, R.; Hasegawa, J.; Ishida, M.; Nakajima, T.; Honda, Y.; Kitao, O.; Nakai, H.; Vreven, T.; Throssell, K.; Montgomery Jr., J. A.; Peralta, J. E.; Ogliaro, F.; Bearpark, M. J.; Heyd, J. J.; Brothers, E. N.; Kudin, K. N.; Staroverov, V. N.; Keith, T. A.; Kobayashi, R.; Normand, J.; Raghavachari, K.; Rendell, A. P.; Burant, J. C.; Iyengar, S. S.; Tomasi, J.; Cossi, M.; Millam, J. M.; Klene, M.; Adamo, C.; Cammi, R.; Ochterski, J. W.; Martin, R. L.; Morokuma, K.; Farkas, O.; Foresman, J. B.; Fox, D. J. Gaussian 16 Rev. C.01, Wallingford, CT, 2016.

10. (a) Becke, A. D., Density-functional exchange-energy approximation with correct asymptotic behavior. Phys. Rev. A. 1988, 38, 3098-3101; (b) Becke, A. D., Density-Functional Thermochemistry. III. The Role of Exact Exchange. J. Chem. Phys. 1993, 98, 5648. 
11. Schafer, A.; Horn, H.; Ahlrichs, R., Fully Optimized Contracted Gaussian-Basis Sets for Atoms Li to Kr. J. Chem. Phys. 1992, 97, 2571.

12. Salomon, O.; Reiher, M.; Hess, B. A. Assertion and validation of the performance of the B3LYP* functional for the first transition metal row and the G2 test set. J. Chem. Phys. 2002, 117, 4729-4737

13. Weigend, F.; Ahlrichs, R., Balanced basis sets of split valence, triple zeta valence and quadruple zeta valence quality for H to Rn: Design and assessment of accuracy. Phys. Chem. Chem. Phys. 2005, 7, 3297-3305.

14. (a) Noodleman, L., Valence Bond Description of Antiferromagnetic Coupling in Transition Metal Dimers. J. Chem. Phys. 1981, 74, 5737; (b) Noodleman, L.; Davidson, E. R., Ligand spin polarization and antiferromagnetic coupling in transition metal dimers. Chem. Phys. 1986, 109, 131; (c) Noodleman, L.; Case, D. A., DensityFunctional Theory of Spin Polarization and Spin Coupling in Iron-Sulfur Clusters. Adv. Inorg. Chem. 1992, 38, 423; (d) Noodleman, L.; Norman, J. G., The Xa valence bond theory of weak electronic coupling. Application to the low-lying states of $\mathrm{Mo}_{2} \mathrm{Cl}_{8}{ }^{4-}$. J. Chem. Phys. 1979, 70, 4903. 